\title{
EFFECTIVE SUPERVISION MEETING PRACTICES: A PRACTICAL TOOL
}

\author{
Euan COUTTS ${ }^{1}$ and Pamela MARSHALL ${ }^{2}$ \\ ${ }^{1}$ University of Canterbury, New Zealand \\ ${ }^{2}$ University of Strathclyde, UK
}

\begin{abstract}
Supervision of student work is a core component of any academic's role. Holding supervision meetings can occupy a large percentage of diaries and yet academics and students often begrudge meetings; supervisees may feel meetings are not fruitful or purposeful, academics may feel students do not maximise on their allocated time, and both can feel there are not sufficient hours in the day for meetings along with other commitments and expectations. Yet very few organisations have meeting guidelines, an "astonishing omission considering the cost of meetings" [1]. Often material relating to academic supervision practices drifts into policy statements "about" supervision rather than practical approaches regarding "how" to supervise. To improve supervision, a new approach focusing on regular, formatted meetings and will be discussed, along with supervision styles. These meetings ensure a consistent format, rolling agenda and mechanism of consistent feedback. This approach facilitated by a paper-based tool, embraced the concept of High Value Meetings (HVMs). This approach is effective by providing students regular, consistent progress feedback, important as "students need to have a clear idea of what is expected of them and whether they are meeting those expectations" [2]. The innovative approach has been employed over the last 5 years with students on product design engineering degrees. Results from a survey of supervisees are presented and discussed along with reflection and recommendations. The desired end result is to transform supervision meetings from a begrudged obligation to effective and efficient use of supervisor and supervisees time; a mutually beneficial undertaking.
\end{abstract}

Keywords: Design education, supervision, meetings, value, formative assessment

\section{INTRODUCTION}

There are no shortage of theories surrounding the supervision or management of individuals and teams in organisational and academic settings. However, in academia these tend to be orientated towards the supervision of research endeavours, and in some cases would appear to serve more as policy statements "about" supervising students rather than practical approaches regarding "how" to supervise. A large percentage of supervision activity, that of undergraduate students, undertaken by academic staff can be overlooked. The practice of supervision, and especially supervision meetings, can fall to the baseline individual traits of a supervisor and their own personal experience in conducting meetings and facilitating discussions, which can vary significantly. Studies have also demonstrated that "new supervisors often found themselves pursuing supervision in a quite solitary way, since supervision (like teaching) tended not to be a topic of collegial interactions... as a result, individuals characterised their supervisory learning emerging from and through personal experience since more formal sources of learning, though desired, were not available" [3]. Our lead author served as an undergraduate and postgraduate masters dissertations coordinator, focussing on design and engineering. When gathering feedback on the programme's supervision is consistently highlighted as both a key positive and a key negative wherein particular trends emerge; inconsistencies encountered between supervisors and students' practices, lack of perceived value from time in meetings, and unrealistic expectations, to list the most prevalent. It should be noted that these trends are evident in commentary and discussion with both supervisees and supervisors. Such observations served to provide the inception for this research into what constitutes effective supervision through a combination of self-reflection and pedagogical literature review. The objective of this paper is to present a new approach which focuses on regular, 
formatted meetings to ensure effectiveness and efficiency, to optimise supervisor and supervisees time. The supervisor style is key and the concept of 'geared supervision' is introduced.

\section{ON SUPERVISION AND THE PROPOSED SUPERVISION APPROACH}

Gatfield and Alpert [4] undertook a review of the literature on this matter with a view to creating a suitable framework specific to $\mathrm{PhD}$ supervision. They classified three supervision practice factors; 'structural', 'support' and 'exogenous'. Wherein 'structural' refers to the supervisor's arrangement setting and organisation, the more managerial approach aspects. 'Support' refers to the interpersonal level of guidance provided, both in terms of topic content and also pastoral or moral support. 'Exogenous' considerations were identified as the fixed variables that fell outside of 'support' and 'structure' such as the work ethic of those involved, personality traits, timetable availability; fixed parameters which are unlikely to alter in the environ or timescale of the project. Gatfield and Alpert [4] note that typically the support factor is that which is varies most and depends upon the supervisor (and institution). However, the authors would argue that the structural factors are equally at the discretion of the supervisor. The authors speculate that there is something missing from these identified factors, the tangible outcomes of engagements, in this case effective feedback (for both parties). Gatfield and Alpert [4] developed their theories into a conceptual model based upon the factors of support and structure which form axes of a grid, based upon the 'managerial grid' of Blake and Mouton [5] which identifies 4 supervision styles. Gatfield and Alpert [4] concluded that "often there was a transition to different styles at different times during the supervision period" indicating a certain dynamism to the style being adopted in response to events or circumstances.

As mentioned in many cases a supervisor's approach is largely determined by their own prior experiences. The author's own supervisory approach is no exception and was consciously designed based upon a combination of their own experiences in a variety of fields ranging from secondary level education to outdoor education combined with formal training and shadowing of colleagues, supported with the use of a paper-based tool. The author subscribes to a Jungian philosophy of student motivation and engagement drawing practical techniques from Herzberg's work, adapting practices regarding employee motivation in an engineering management context [6] part of what Gatfield and Alpert [4] referred to as exogenous considerations. It is the author's experience that students will on an individual basis have an affinity for particular "motivators" or "inhibitors" (or Herzberg's "hygienic factors") which will either heighten or dampen their engagement in their own learning and progress in their projects. This is significant in supervision practices; over time developing an understanding of such factors serves to create a more proactive student work ethic rather than relying on delivery to a particular deadline alone; "learners have different strategies, approaches, patterns of abilities, and learning styles that are a function of the interaction between their heredity and their prior experiences" [2]. Proactive management of these is key, scenarios may yield high reward or high risk and managing the resulting reactions of individuals can have significant impact. For many undergraduate students their projects and dissertations generally represent the biggest determinate in their degree outcomes. The management of risk is key, regardless of whether or not the risk is genuine or perceived; the outcome is the same; the perception becomes the reality of the situation, in the more significant circumstances this may lead to panic. While exploring this avenue of reflection a surprising (or perhaps in retrospect not entirely unsurprisingly) amount of overlap and congruity in theories on the subject of supervision and management in different arenas becomes evident. One of the key principles involved in the author's approach is different "leadership styles" [7]. Rather than viewing supervision as a grid or "states", the authors consider this to be more akin to a spectrum, along which one may move up or down. Visualised by a simple gauge that is bounded by two polarised extremes of leadership style; autocratic and laissez-faire, demonstrated in Figure 1. The extremes would indicate either a very rigid and formalised "hands-on" style or a loose, informal "hands-off" style. In the authors' experience it is only effective to move incrementally along this spectrum, trying to abruptly adopt a different style is jarring and unlikely to be effective. Where Gatfield and Alpert [4] refined their model to prescriptively reflect changes in supervisory style progress in relation to the stage of the supervisee's project, it is the authors' experience it is better not to be too rigid in applying a particular style to a particular project stage but rather to the individual student, as supervision is an interpersonal dynamic, it follows suit that the style should be applied to the student and their characteristics (or their "motivators" or "inhibitors") rather than progress. However, it is agreed that "in general a candidate will be most successful if a supervisor can operate a range of supervisory styles" [4]. An effective 
supervisor should be able to dynamically alter their style in response to what motivates or inhibits any given student. Understanding what motivates a student allows the student-supervisor dynamic to move through the "gears" of engagement more rapidly to achieve a smooth "cruise" of consistent student working and achieve their desired outcome within a suitable timeframe. While commencing with a more formal and hands on approach this can be progressed to a more balanced level allowing a student more autonomy while acknowledging that it is possible in principle to overshoot this and become too detached. This practice of "geared" supervision was heavily influenced by prior experience; an approach of the authors design, a simple analogy-based method of delivering effective bespoke supervision practices to students. These practices have evolved over time through a combination of peer observation and engagement, continuing professional development and pedagogical research.

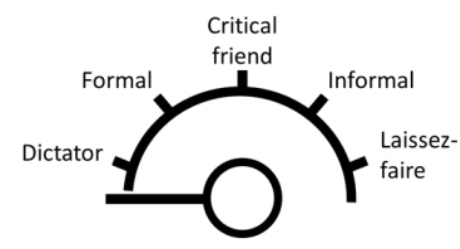

Figure 1. Visualisation of "geared" supervision spectrum

The supervision style adopted in a meeting should be carefully considered and in the author's experience this should be determined by the nature of the interpersonal dynamic between the supervisor and student and dependent upon the student's "motivators" and "inhibitors". No two students will respond in the same way to a particular style, some will respond better to the formal structure of an autocratic "boss", others to a friendlier and social style, and there will be those who respond to some combination. In the context of the "leaderships styles" spectrum in the author's experience it is often best to start slightly closer to the autocratic end of the spectrum, as the students will require structure and a perception of authority to begin with. A supervisor should not be jumping between far ranging gears, they must be moved through incrementally which is why it is important to start in a position of relative authority, if a supervisor starts too amiably and as the project progresses it becomes apparent that a more formal approach may be required, it is harder to move down the gears than move up. All the while ensuring good practice for HVMs when engaging with students.

\section{ON HIGH VALUE SUPERVISION MEETINGS}

Meetings are such a synonymous part of contemporary working culture that it is often incorrectly assumed that everyone understands the term "meeting", this may indeed be part of the reason why there is so much general frustration surrounding meetings in the modern workplace. Following extensive review of literature on the matter Marshall and Whitfield [8] concluded that a meeting is "a synchronous focussed gathering of two or more participants for a specific purpose or purposes $a$ priori". They further defined a high value meeting (HVM) as "[a meeting] that addresses an important organisational need through achieving its defined purpose effectively and efficiently" [8] where value is considered to be a "contribution to satisfy need" [9]. It is therefore important to ensure that supervision meetings are HVMs. With this definition in mind it is reasonable to suggest that supervision meetings are meetings between a supervisor and supervisee (in academia generally an academic and a student) for the specific purpose of discussing progress on a project and providing or receiving guidance and support effectively and efficiently throughout the duration of the project. We must then consider what constitutes effective and efficient progress reporting, guidance and support. To this end a standard and consistent record sheet is utilised. Originally developed by a colleague, Prof. Duffy, University of Strathclyde, the "progress meeting sheet", later renamed to "progress and feedback record sheet" or PRF, is demonstrated in Figure 2. This was originally developed for PhD supervision but has adapted well for undergraduate students, more details can be found in Duffy et al [10]. The scope of the approach is wide and can be utilised in all student projects: undergraduate; post graduate taught; and post graduate research. The logic in the use of a standard sheet for recording meetings is several fold. It provides a mechanism of tracking progress through a project, delivers a mechanism of planning for activities between meetings, serves as a record for both supervisor and supervisee, and provides iterative formal written feedback dynamically throughout the project. 

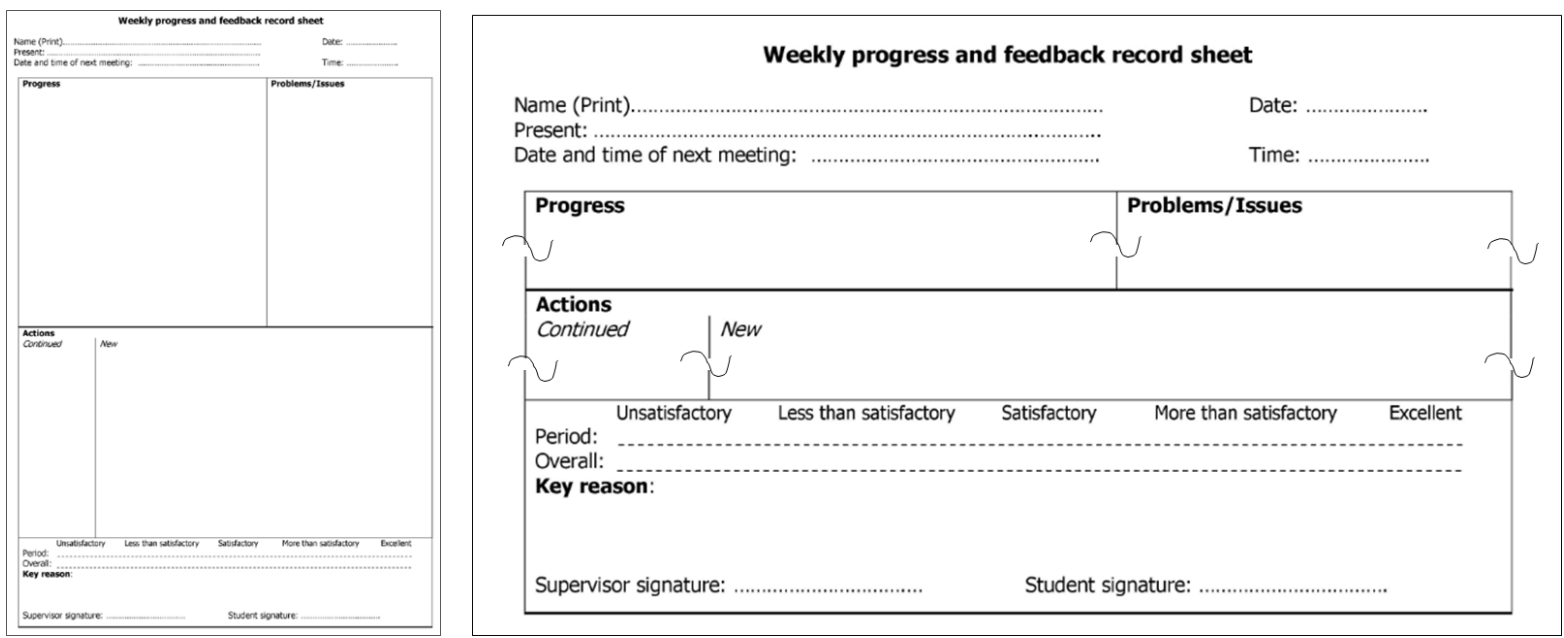

Figure 2. Progress and feedback record sheet (PRF). On left full sheet, on right cropped relevant excerpts for legibility

Each meeting the students are asked to complete the sheet updating progress on agreed tasks and then reflect upon their progress on a scale from "unsatisfactory" to "excellent". This helps to ensure that supervision meetings are high value in a number of ways: provides a rolling agenda ensuring meeting efficiency, provides formal written feedback regularly, ensures active participation by all parties, ensures preparation prior to meetings, ensures clear uncluttered records of meetings and agreed activities (particularly helpful in reducing the scope for acrimonious misunderstandings), and lastly creates a sense of project ownership, through the written record and signatures of both parties. In summary, for time in meetings to be well spent they must be both effective and efficient, in our approach this is largely facilitated by applying an appropriate style and the use of the PFR sheet.

\section{METHODS}

The preceding 5 years (2013-2018) of supervisees were surveyed by means of a specifically developed qualitative and quantitative questionnaire, to gather information on the effectiveness of the proposed supervisory approach. As these former supervisees had since graduated and moved to various global locations, the professional networking site LinkedIn provided a platform to make contact and circulate the survey. Of a possible 93 respondents 63 were found to be active LinkedIn members, therein 43 accepted connection requests within the designated 4-week period of the survey, in this time a total of 34 responses were collected; a little over one third representing a cross section of previous students. No students were selected based upon any form of preference to mitigate bias in the sample population. The questionnaire of 30 questions consisted of a mix of structured and open-ended questions. The questionnaire was anonymous to encourage completion and increase honest feedback.

\section{RESULTS \& DISCUSSION}

The results gathered from the quantitative aspects of the questionnaire are presented as percentage responses in the form of a heat map in Figure 3. The other questions were either background information or open-ended questions. The results on the whole are encouragingly positive, with almost all responses indicating support for the proposed approach over the last 5 years of supervision activities. The highest instances of neutral or negative responses would appear to occur in relation to the progress meeting sheets and reflection of whether or not the approach has had an influence on graduates' subsequent professional practices. 


\begin{tabular}{|c|c|c|c|c|c|}
\hline Question/Response & 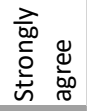 & $\frac{\searrow}{\frac{\Phi}{00}}$ & 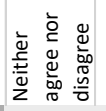 & 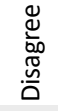 & 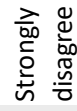 \\
\hline The meetings took place at the right frequency & $59 \%$ & $41 \%$ & $0 \%$ & $0 \%$ & $0 \%$ \\
\hline The meetings were the appropriate duration & $41 \%$ & $53 \%$ & $3 \%$ & $3 \%$ & $0 \%$ \\
\hline Equal participation was encouraged & $53 \%$ & $32 \%$ & $12 \%$ & $0 \%$ & $0 \%$ \\
\hline I was able to contribute fully and get what I needed from the meetings & $47 \%$ & $44 \%$ & $6 \%$ & $0 \%$ & $0 \%$ \\
\hline The meetings allowed for useful and valuable discussion amongst peers & $62 \%$ & $38 \%$ & $0 \%$ & $0 \%$ & $0 \%$ \\
\hline Preparation on my part was important to the meetings & $55 \%$ & $39 \%$ & $3 \%$ & $3 \%$ & $0 \%$ \\
\hline The meetings fulfilled their purpose & $52 \%$ & $48 \%$ & $0 \%$ & $0 \%$ & $0 \%$ \\
\hline The meeting progress sheets helped me prepare for the meetings & $16 \%$ & $53 \%$ & $25 \%$ & $6 \%$ & $0 \%$ \\
\hline The meeting progress sheets helped me manage my work throughout the project & $25 \%$ & $41 \%$ & $25 \%$ & $9 \%$ & $0 \%$ \\
\hline The supervisor gave sufficient guidance and support with my project & $62 \%$ & $34 \%$ & $0 \%$ & $3 \%$ & $0 \%$ \\
\hline Contactable and engaged in communications in an appropriate timeframe. & $66 \%$ & $34 \%$ & $0 \%$ & $0 \%$ & $0 \%$ \\
\hline Gave appropriate quality of feedback, which could be through verbal or written communication & $59 \%$ & $38 \%$ & $0 \%$ & $0 \%$ & $0 \%$ \\
\hline Level of guidance, engagement and response that was appropriate to my own engagement & $62 \%$ & $34 \%$ & $3 \%$ & $0 \%$ & $0 \%$ \\
\hline I feel that the supervisor made a conscious effort in supervision & $72 \%$ & $24 \%$ & $3 \%$ & $0 \%$ & $0 \%$ \\
\hline The supervision approach helped to shape my work and project & $45 \%$ & $52 \%$ & $3 \%$ & $0 \%$ & $0 \%$ \\
\hline I would consider the supervisory meetings to be high value meetings & $48 \%$ & $52 \%$ & $0 \%$ & $0 \%$ & $0 \%$ \\
\hline The supervisory experience has shaped my professional practices beyond my course & $31 \%$ & $14 \%$ & $48 \%$ & $7 \%$ & $0 \%$ \\
\hline
\end{tabular}

Figure 3. Responses to quantitative questionnaire questions

As previously mentioned in the paper it is considered that there are several key aspects to any supervisory approach; the supervision style, meeting conduct (ensuring high value meetings) and feedback. Each of these areas will be now be discussed in relation to the results generated, both quantitative and qualitative, and literature on the matter. It would appear from the results that students responded positively to the supervisor style, while it is not possible to determine where on the supervisors' style spectrum at any given point in a project this may be referring, the concept of an overall "critical friend" would appear to ring true. This is further evidenced by responses to qualitative open choice questions. In relation to questions specifically about supervisory style: "A professional supervisory style lead to, in my opinion, a more professional output in terms of the project hand in."; "It was very professional and appreciated. Particularly in times of high stress."; "Blunt, but most helpful. My preferred style."; "Encouraging and helpful."

It was established earlier in the paper that HVMs in the supervision context are meetings between a supervisor and supervisee for the specific purpose of discussing progress on a project and providing or receiving guidance and support thereon throughout the duration of the project, effectively and efficiently. In order to assess whether or not this was the case respondents were asked (without prompt or any extra explanation) "In your own words, what did you think the purpose of the meetings was?" a selection of typical answers were: "To get constructive and critical feedback on work we had completed/were about to carry out. Also, for you to chivvy us forward!"; "To determine if correct method and practice was being pursued. To encourage hard work and thoughtfulness and deep understanding of the research."; "To assist in achieving the objective of the class to the best of my ability."; "To evaluate what had been done to that point, what still needed to be done and how far along in the progression from start to end of project I felt I was."

It is encouraging that without any prompting that the majority of responses represent some variation of the intended purpose. In addition, all the respondents strongly agreed or agreed that the purpose was achieved, a key aspect of an HVM. Further encouraged by how frequently constructive feedback is mentioned in responses, particularly when considering feedback is consistently highlighted as an area of student dissatisfaction in NSS results throughout the UK. These responses would appear to indicate, in conjunction with the quantitative question responses in Figure 3, including when asked specifically on the value of meetings, that the meetings were indeed of high value. On the subject of the PFRs opinion diverged a little more, while on the whole still positive there was a greater spread of opinion see Figure 3, supported by the qualitative open questions on the matter. The responses ranged from positive: "It was very easy to keep track of the tasks which were undertaken/in progress"; "Worked for me as it is a supervised checklist. I can get lazy if I follow my own checklist"; "Clear agenda of what needed to be completed"; To negative: "Progress scale at the bottom of the sheet can be very discouraging to see if one is falling behind." It appears that in their intended purpose of serving as a rolling agenda and means of recording progress and feedback in each meeting they were successful but 
that perhaps they would benefit from revision in their design and to incorporate some more subjective aspects of reflection. Many students also expressed a desire for the PFR to be made digital and online, perhaps reflecting the increasingly digital nature of student work, and perhaps of contemporary working culture in general. Another key aspect of HVMs is that those involved are active participants not simply attendees. A concept which was intended to be imbued in our approach through the means of asking students to prepare their PFRs in advance and then complete them in the course of the meetings. The effect of this is measured in questions relating to preparation and participation: "I would try to show that I am at the stage I should be in my project plan. I would bring evidence of this to discuss at the meeting. Allowing me to discuss where I had problems and gain valuable feedback from the meetings."; "Ensuring that all tasks were completed up-to-date" \& "I knew what elements I needed support with"; "[Supervisor] would give us targets for our weekly meetings so that we'd have a certain amount of work done and could reflect on in the next meeting. We would normally agree on a task list for the next meeting."; "Completion of agreed objectives and plan for next steps (or conformance plan of how to catch up), preparation of topics wanting to be discussed relating to the Individual Project)." This would appear to indicate that the use of PFRs helped to encourage a sense of investment in the project by students, but importantly also a sense of investment in the meetings being attended, they were not simply a date and time where you turned up to chat to a member of staff, they were focused and part of an ongoing body of work building towards a project outcome.

\section{CONCLUSIONS}

To conclude, the results would appear to indicate an encouraging positive response to the proposed approach and associated paper-based tool, albeit if some refinement would be beneficial. Importantly feedback is provided throughout the meeting discussion, in the form of oral discussion accompanied by written feedback on progress against agreed targets following any significant project milestones. Fostering a sense of project ownership and responsibility ensures students are engaged in each meeting and not simply lulled into a "passive" state of deferring to an academic member of staff; which may lead a student to incorrectly expect to be "told what to do" in their projects. Vital as "incorporation of active learning strategies into the classroom is critical in order to reach Millennial students" [11]. It is key the student is an active participant in the meeting and not just an attendee. The responses gained from students in the survey will be used to further refine the approach in order to achieve the longterm goal to transform supervision meetings from a begrudged obligation to effective and efficient uses of both a supervisor and supervisees time; a mutually beneficial undertaking.

\section{REFERENCES}

[1] Woods R.H. and Berger F. Making Meetings Work. Cornell Hotel and Restaurant Administration Quarterly, 2016. 29(2): p. 100-106.

[2] Council N.R. Evaluating and improving undergraduate teaching in science, technology, engineering, and mathematics. 2003: National Academies Press.

[3] McAlpine L. Doctoral supervision: Not an individual but a collective institutional responsibility. Infancia y Aprendizaje, 2014. 36(3): p. 259-280.

[4] Gatfield T. and Alpert F. The supervisory management styles model. in Annual International Conference Of The Higher Education Research And Development Society Of Australasia (Herdsa). Perth, Australia: HERDSA. 2002.

[5] Blake R.R. and Mouton J.S. The Managerial Grid; Key Orientations for Achieving Production through People. 1968.

[6] Herzberg F., Mausner B. and Snyderman B.B.J.I. New York, The Motivation to Work, John Wiley \& Sons. 1959. 195.

[7] Ferrero F. White water safety and rescue. 2006: Pesda Press.

[8] Marshall P. et al. A new model for high value meetings. Paper presented at 22nd EurOMA 2015, Neuchâtel, Switzerland, 26/06/15 - 1/07/15, . 2015.

[9] Reber M. and Duffy A. Value Centred Design: Understanding the nature of value. 2005.

[10] Duffy A., Siska S. and Imron T. The knowledge nugget. 2013: LAMBERT Academic Publishing.

[11] Roehl A. et al. The flipped classroom: An opportunity to engage millennial students through active learning strategies. 2013. 105(2): p. 44-49. 